\title{
High Tibial Opening Wedge Osteotomy in Osteoarthritis with Varus Knee
}

\author{
Ismael Ahmed Yassein, Ehab Abd El Maboud Elzehad, Yasser Mohamed Ali Mohamed* \\ Orthopedic Surgery Department, Faculty of Medicine, Al-Azhar University \\ * Corresponding author: Yasser Mohamed Ali Mohamed, E-mail: dr.yasor10@gmail.com
}

\begin{abstract}
Background: High tibial osteotomy was first described in 1958 as a successful treatment for moderate to severe unicompartmental, degenerative arthritis of the knee associated with angular deformity. Malalignment is frequently associated with knee arthrosis and can influence the mechanical load through either the medial or the lateral compartment.
\end{abstract}

Aim of the work: Investigation of the clinical and radiographic results of opening-wedge high tibial osteotomy and fixated by locked compression plate, when used to as surgical treatment of osteoarthritis and varus deformity.

Patients and methods: The study took place at Al Azhar University Hospital \{Elhussein and Bab EL Sharia\}.

It was a prospective study on 20 consecutive patients who had knee osteoarthritis and varus knee deformity. They were treated by surgical intervention by opening wedge high tibial osteotomy applied by $\mathrm{T}-$ locked plate, between September 2016 to April 2019. The procedures are carried out under spinal anesthesia.

Results: There was a significant improvement in the pain level after surgery when compared to before surgery. Postoperatively, 16 patients (80\%) were found to have no pain. Pre-operatively 19 patients (95\%) had full range of knee motion, and only one patient had hyperextension. Post-operatively, all patients had maintained their full knee extension. Postoperatively, $60 \%$ of the patients showed normal alignment, $10 \%$ valgus (mean: $1^{\circ}$ valgus) and $30 \%$ still varus (mean: $2.33^{\circ}$ varus, range: $1-4^{\circ}$ ).

Conclusion: The patients in this study were satisfied with the results. Younger patients planning for HTO should be advised about the benefits and risks of the procedure, specifically mentioning kneeling and scar formation.

Keywords: High Tibial Opening Wedge Osteotomy, Osteoarthritis, Varus Knee.

\section{INTRODUCTION}

High tibial osteotomy was first described in 1958 as a successful treatment of acute to severe acute to severe arthritis, and degenerative knee arthritis associated with angular deformity ${ }^{(1)}$. Bad pigmentation is often associated with knee arthroplasty and can affect mechanical load through the median or lateral space. Increased pressure on the articular cartilage may lead to a higher risk of arthritis ${ }^{(2)}$.

Several studies have analyzed the results of this process with respect to age, activity, sex, degree of neuropathy, weight, pre-treatment and preoperative and post-operative treatment ${ }^{(3)}$.

The aim of bone, regardless of anatomical or technical location, is to re-establish the weight line as close as possible naturally to reduce pressure through the central and lateral compartments or ligament structures ${ }^{(4)}$. HTO is the reduction of load by turning the mechanical axis towards the side chamber.

It is an effective surgical procedure for young and middle-aged patients with osteoarthritis of the knee. The results suggest that the factors predicting positive outcomes include relative weight loss, angular correction, and a general low level of disease $^{(5)}$.

\section{AIM OF THE WORK}

The aim of this study was to investigate the clinical and radiographic results of opening-wedge high tibial osteotomy and fixated by locked compression plate, when used as surgical treatment of osteoarthritis and varus deformity.

\section{PATIENTS AND METHODS}

The study took place at Al Azhar University Hospital \{Elhussein and Bab EL Sharia\}. It is a prospective study on 20 consecutive patients who had knee osteoarthritis and varus knee deformity. They were treated by surgical intervention by opening wedge high tibial osteotomy applied by $\mathrm{T}-$ locked plate, between September 2016 to February 2019. The procedures are carried out under spinal anesthesia.

The study was approved by the Ethics Board of Al-Azhar University and an informed written consent was taken from each participant in the study.

All patients underwent the same preoperative clinical, radiological examination and Lysholm score system. 
Lysholm score is 100 point and consists of eight components; this score is the best tools currently available to asses result of surgical management of OA Knee with OWHTO.

\section{Patient Selection \\ Inclusion criteria}

1- Patients 30-60 years old.

2- Varus malalignment of the limb $<15^{\circ}$.

3- No patellofemoral symptoms.

4- Isolated medial activity- related joint line pain.

5- Full extension.

6- Range of motion $>100^{\circ}$.

7- Stable knee.

8- Normal lateral component, and No meniscectomy.

\section{Exclusion criteria}

1- Patient above 60 years.

2- Rheumatoid arthritis.

3- Severe patellofemoral symptoms.

4- Flexion contracture $>25$.

5- Range of motion $<75^{\circ}$.

6- Inflammatory disease.

7- Patellofemoral arthrosis grade IV-V.

8- Severe osteoporosis.

9- Extra-articular deformity.

10- Lateral meniscectomy.

11- Bone healing disorders.

\section{Implant Used:}

- The T- Locked Plate for medial opening wedge osteotomy.

- Combi-holes combine a dynamic compression unit (DCU) hole with a locking-screw hole. This allows the surgeon either to insert a standard bicortical screw, or a locked screw.

- Locking screws in the head of the plate for a secure support.

- The head of the locking screw is threaded, which gets locked to the plate as it is tightened

\section{Surgical Technique \\ Positioning}

The patient was placed supine on the operating table. A radiolucent extension was applied to enable fluoroscopic examination.

\section{Surgical Anatomy}

The bony landmarks should be palpated and marked prior to incision, including the femoral condyles, tibial plateau, and patella. Structures at risk include the neurovascular bundle in the popliteal fossa. great care should be taken to meticulously dissect the posterior aspect of the proximal tibia and place a retractor and sponges between bone and soft tissue for protection. A pre-operative MRI could be useful to rule out an aberrant take off of the anterior tibial artery, which courses anteriorly, rather than posteriorly, to the popliteus muscle in $2 \%$ of patients ${ }^{(9)}$.

\section{Technical Steps}

- Opening Wedge High Tibial Osteotomy

- Guide Pin Insertion

- Osteotomy Cut

Osteotomy Distraction

Plate Fixation

Incision Closure

\section{Data management and statistics}

Data were collected, revised and edited into a master table using Microsoft Excel 2016. Data were revised, coded and entered to the statistical package for social science (SPSS) version 22. P: The probability/significance value: $\mathrm{P}$ value $>0.05(\mathrm{NS})$ not significant, $\mathrm{P}$ value $<0.05 *$ Significant, $\mathrm{P}$ value $<$ $0.01 * *$ Highly Significant at.

\section{RESULTS}

Patients were followed up at 2, 4, 6 weeks and 2 months postoperatively (mean $8 \pm 3.5$ weeks). Twenty patients began the study and completed the follow up period.

Table (1): Demographic characteristics of study participants $(\mathrm{N}=20)$

\begin{tabular}{|l|c|c|}
\hline \multicolumn{1}{|c|}{ Variable } & Mean \pm SD & Range \\
\hline Age (years) & $42.9 \pm 7.2$ & $32-60$ \\
\hline Variable & $\mathbf{N}$ & $\boldsymbol{\%}$ \\
\hline Sex: & & \\
Male & 7 & 35.0 \\
Female & 13 & 65.0 \\
\hline
\end{tabular}

Table (2): Presenting symptoms among study participants $(\mathrm{N}=20)$

\begin{tabular}{|l|c|c|}
\hline \multicolumn{1}{|c|}{ Variable } & N & \% \\
\hline Complaint: & & \\
Deformity & 3 & 85.0 \\
Pain & 17 & 15.0 \\
\hline Side: & & \\
Right & 5 & 25.0 \\
Left & 15 & 75.0 \\
\hline
\end{tabular}


Table (3): Radiological findings of the involved patients (Pre vs. Post)

\begin{tabular}{|c|c|c|c|}
\hline No & $\begin{array}{c}\text { Pre-operative degree } \\
\text { of varus }\end{array}$ & $\begin{array}{c}\text { Post-operative degree } \\
\text { of varus }\end{array}$ & $\begin{array}{c}\text { Degree of } \\
\text { Varus correction }\end{array}$ \\
\hline 1 & $8^{\circ}$ & $0^{\circ}$ & $8^{\circ}$ \\
\hline 2 & $13^{\circ}$ & $2^{\circ}$ & $11^{\circ}$ \\
\hline 3 & $13^{\circ}$ & $1^{\circ}$ valgus & $14^{\circ}$ \\
\hline 4 & $12^{\circ}$ & $0^{\circ}$ & $12^{\circ}$ \\
\hline 5 & $10^{\circ}$ & $0^{\circ}$ & $4^{\circ}$ \\
\hline 6 & $8^{\circ}$ & $4^{\circ}$ & $14^{\circ}$ \\
\hline 7 & $14^{\circ}$ & $0^{\circ}$ & $14^{\circ}$ \\
\hline 8 & $14^{\circ}$ & $0^{\circ}$ & $12^{\circ}$ \\
\hline 9 & $12^{\circ}$ & $0^{\circ}$ & $14^{\circ}$ \\
\hline 10 & $10^{\circ}$ & $4^{\circ}$ & $9^{\circ}$ \\
\hline 11 & $14^{\circ}$ & $0^{\circ}$ & $8^{\circ}$ \\
\hline 12 & $10^{\circ}$ & $1^{\circ}$ & $12^{\circ}$ \\
\hline 13 & $8^{\circ}$ & $0^{\circ}$ & $9^{\circ}$ \\
\hline 14 & $12^{\circ}$ & $0^{\circ}$ & $8^{\circ}$ \\
\hline 15 & $9^{\circ}$ & $0^{\circ}$ & $10^{\circ}$ \\
\hline 16 & $8^{\circ}$ & $0^{\circ}$ & $7^{\circ}$ \\
\hline 17 & $11^{\circ}$ & $1^{\circ}$ & $8^{\circ}$ \\
\hline 18 & $6^{\circ}$ & $1^{\circ}$ valgus & $11^{\circ}$ \\
\hline 19 & $10^{\circ}$ & $2^{\circ}$ & $\mathbf{1 0 . 0 5}^{\circ} \pm \mathbf{2 . 9}$ \\
\hline 20 & $11^{\circ}$ & $0^{\circ}$ & $\mathbf{6}^{\circ} \mathbf{- 1 4 ^ { \circ }}$ \\
\hline Average degree $\pm \mathbf{S D}$ & $\mathbf{1 0 . 6 5}^{\circ} \mathbf{2 . 3}$ & $\mathbf{0 . 6} \pm \mathbf{1 . 4}$ & \\
\hline range & $\mathbf{6}^{\circ} \mathbf{- 1 4}$ varus & $\mathbf{1}^{\circ}$ valgus- ${ }^{\circ}$ varus & \\
\hline & & & \\
\hline
\end{tabular}

There was a significant improvement in the varus degree after surgery when compared with before surgery. Postoperatively, $60 \%$ of the patients showed normal alignment, $10 \%$ valgus (mean: $1^{\circ}$ valgus) and $30 \%$ still varus (mean: $2.33^{\circ}$ varus, range: $1-4^{\circ}$ ).

Table (4): Post-operative lower-limb goniometry.

\begin{tabular}{|l|r|r|r|}
\hline \multirow{2}{*}{ Varus } & Degree & Number & $\begin{array}{c}\text { Percentage } \\
(\mathbf{\%})\end{array}$ \\
\hline Normal alignment & $\mathbf{1 - 3}$ & 4 & 20 \\
\cline { 2 - 4 } & $\mathbf{3}$ & 2 & 10 \\
\hline \multirow{2}{*}{ Valgus } & $\mathbf{1 - 3}$ & 12 & 60 \\
\cline { 2 - 4 } & $>\mathbf{3}$ & 0 & 10 \\
\hline
\end{tabular}

Table (5): Varus stress test.

\begin{tabular}{|l|r|c|}
\hline $\begin{array}{l}\text { Lateral joint } \\
\text { opening }\end{array}$ & Number & Percentage (\%) \\
\hline Mild & 20 & 100 \\
\hline Moderate & 0 & 0 \\
\hline Severe & 0 & 0 \\
\hline
\end{tabular}

There was a significant improvement in the lateral joint opening after surgery when compared with before surgery. Postoperatively, all patients (100\%) were found to have mild lateral joint opening $(0-5 \mathrm{~mm})$. Table (6): Patient knee function

\begin{tabular}{|l|c|c|}
\hline & Number & Percentage (\%) \\
\hline Normal & 16 & 80 \\
\hline Nearly normal & 4 & 20 \\
\hline Abnormal & 0 & 0 \\
\hline Severely abnormal & 0 & 0 \\
\hline
\end{tabular}

It was found that there was a significant improvement in the knee function after surgery when compared with before surgery. While all 20 patients $(100 \%)$ considered their knee abnormal or severely abnormal, preoperatively, 16 patients $(80 \%)$ found their knee normal postoperatively.

Table (7): Pain scale postoperative

\begin{tabular}{|l|c|c|}
\hline Pain & Number & Percentage (\%) \\
\hline No pain & 16 & 80 \\
\hline
\end{tabular}


There was a significant improvement in the pain level after surgery when compared with before surgery. Postoperatively, 16 patients $(80 \%)$ were found to have no pain.

Table (8): Swelling postoperative

\begin{tabular}{|c|c|c|}
\hline Swelling & Number & Percentage (\%) \\
\hline No swelling & 17 & 85 \\
\hline
\end{tabular}

There was a significant improvement in the swelling level after surgery when compared with before surgery. Postoperatively, 17 patients $(85 \%)$ were found to have no swelling.

Table (9): Final evaluation according to Lysholm score.

\begin{tabular}{|c|c|c|}
\hline & Number & Percentage (\%) \\
\hline Excellent (95-100) & 15 & 75 \\
\hline Good (84-94) & 5 & 25 \\
\hline Fair $(\mathbf{6 5 - 8 3 )}$ & 0 & 0 \\
\hline Poor $(<\mathbf{6 5})$ & 0 & 0 \\
\hline
\end{tabular}

There was a significant improvement in the final Lysholm knee scoring after surgery when compared with before surgery. Preoperative mean Lysholm score was $38.5 \pm 8.87$ while the postoperative mean Lysholm score was $95.6 \pm 1.9(P$ value $=0.001)$.

\section{DISCUSSION}

This was a retrospective study on twenty patients who underwent surgical management of osteoarthritis and varus knee deformity. Current study address High tibial opening wedge osteotomy in osteoarthritis with varus knee.

The goals of surgery OWHTO was to reduce the load on the medial compartment by shifting the mechanical axis towards the lateral compartment as an effective surgical procedure in young and middle-aged patients with medial compartment knee osteoarthritis. Findings indicated that factors predicting favourable outcomes included decreased relative weight, increased angle correction, and lower overall level of disease ${ }^{(5)}$.

In this study, there was application of locking compression plate in all patient. The ap-propriate tibial proximal locking plate was placed at the anteromedial cortex of the tibia. The special design of the holes allowed the insertion of the lock screws or conventional screws into the plate if required. The proximal selftapping long bolts were inserted into the special platemounted drill sleeves after the lengths were measured. In proximal segment, locking screws were placed into the cancellous bone, while in the distal tibial shaft, bicortical or monocortical fixation was used. The screws were tightened gradually and the osteotomy was carefully monitored to avoid the loss of correction. No drain was used and the subcutaneous layer and skin were closed with interrupted sutures. Elastic compression drape was applied over the entire leg ${ }^{(7)}$.

The pool of patients consisted of seven men and thirteen women. Five patients had right extremity involvement, whereas the fifteen patients had involvement of the left extremity.

In this study, ages of patients ranged from 35 to 60 years old and average age about 42 years.

In this study, all patient had OA Knee, and 17 patients complained from pain during walking and rest, 3 patient only complained from knee varus deformity,

There was a significant improvement in the pain level after surgery when compared to before surgery. Post-operatively, 16 patients $(80 \%)$ were found to have no pain. Pre-operatively, 19 patients $(95 \%)$ had full range of knee motion and only one patient had hyperextension. Post-operatively, all patients had maintained their full knee extension.

In this study all patients were evaluated according to Lysholm knee scoring. There was a significant improvement in the final Lysholm knee scoring after surgery when compared with before surgery. Pre-operative mean Lysholm score was $38.5 \pm$ 8.87 while the post-operative mean Lysholm score was $95.6 \pm 1.9(P$ value $=0.001)$.

Naudie et al. ${ }^{\left({ }^{8}\right)}$ reported that seventeen knees with instability rather than osteoarthritis were treated with an opening wedge high tibial osteotomy. Functional results were evaluated based on the scoring systems by Lysholm and Tegner and using a 5-point analogue scale to assess knee stability and satisfaction. Patients were followed for 56 months. All patients had an increase in their activity level. All but one was satisfied with their outcome. Radiographic results showed a correction of the mechanical axis to about $46 \%$ toward the lateral side.

Hernigou et al. (4) using an opening wedge technique, treated 93 knees. At a 5-years follow-up, $90 \%$ of the knees had good or excellent results. The results deteriorated over time, and after 10 years, $45 \%$ of the patients had excellent or good results.

Koshino et al. ${ }^{(7)}$ studied the outcomes of 21 knees that underwent opening wedge high tibial osteotomy. The mean age was 66.6 years, and the patients were followed for an average of 78.6 months. Two hydroxyapatite wedges were placed in each osteotomy site. The mean knee and functional scores of the American Knee Society improved from 60.2 and 48.1 to 94.3 and 93.1 , respectively. No recurrence of varus deformity was noted in any patient.

In this study, all patients showed that there was a significant improvement in the knee function after surgery when compared to before surgery. While all 20 
patients $(100 \%)$ who considered their knees abnormal or severely abnormal, pre-operatively, 16 patients $(80 \%)$ of them found their knees became normal postoperatively.

In this study, all patients underwent radiological evaluation and assessment of the degree of varus alignment by:

(A) Full-weight-bearing long-leg standing anteroposterior radiographs were done to determine the angle of the extremity and the desired degree of correction

(B) A lateral non-weight-bearing radiography of the knee at $30^{\circ}$ of flexion was used to measure the posterior tibial slope as well as the patellar height.

There was a significant improvement in the varus degree after surgery when compared to before surgery. Post-operatively, $60 \%$ of the patients showed normal alignment, $10 \%$ showed valgus (mean: $1^{\circ}$ valgus) and $30 \%$ still varus (mean: $2.33^{\circ}$ varus, range: $1-4^{\circ}$ ). In this study, there was a significant improvement in the lateral joint opening after surgery when compared to before surgery. Post-operatively, all patients (100\%) were found to have mild lateral joint opening $(0-5 \mathrm{~mm})$. Only one patient $(10 \%)$ experienced mild superficial infection postoperatively with $38^{\circ} \mathrm{C}$ fever, which resolved on I.V antibiotics without adverse effects on the final outcome and no need for debridement. In this study, one patient had delayed union and under correction postoperatively $(5 \%)$.

\section{CONCLUSION}

The patients in this study were satisfied with the results. Younger patients planning for HTO should be advised about the benefits and risks of the procedure, specifically mentioning kneeling and scar formation. They should also routinely be informed about hardware removal later on. As long as adequate patient selection, precise operative correction, and careful management are achieved.

There is a good chance of positive and longlasting results with HTO in the treatment of unicompartmental osteoarthritis in the medial joint space, varus deformity less than 15 degrees with no flexion deformity and good patient motivation to comply with post-operative rehabilitation program in this age group. The results of this preliminary study encouraged us to further pursue earlier correction of mild-to-moderate tibia vara and look forward to its medium and long-term results.

\section{REFERENCES}

1- Lobenhoffer P, Agneskirchner JD (2003): Improvements in surgical technique of valgus high tibial osteotomy. Knee Surgery, Sports Traumatololy, Arthroscopy. Official Journal of the ESSKA., 11 (3): 132-8.

2- Poignard A, Flouzat CH, Amzallag JP (2010): Revisiting high tibial osteotomy: fifty years of experience with the opening-wedge technique. J Bone Joint Surg Am., 92 (2): 187-195.

3- Valkering, KP, Bekerom MP, Kappelhoff, FM, Albers GH (2009): Complications after tomofix medial opening wedge high tibial osteotomy. The Journal of Knee Surgery, 22 (3): 218-25.

4- Hernigou P, Medevielle D (1987): Proximal tibial osteotomy for osteoarthritis with varus deformity: a ten to thirteen year follow up study. J Bone Joint Surg Am., 69: 332-354.

5- Gaasbeek RD, Nicolaas L, Rijnberg WJ, van Loon CJ, van Kampen A (2010): Correction accuracy and collateral laxity in open versus closed wedge high tibial osteotomy. A one year randomized controlled study. Int Orthop., 34: 201-207.

6- Fred F, Gabriel H (2011): Normal Anatomy and Biomechanics of the Knee, Sports Med Arthrosc Rev., 19: 82-92.

7- Koshino T, Murase T, Saito T (2003): Medial opening-wedge high tibial osteotomy with use of porous hydroxyapatite to treat medial compartment osteoarthritis of the knee. J Bone Joint Surg Am., 85: 78-85.

8- Naudie DD, Amendola A, Fowler PJ (2004): Opening wedge high tibial osteotomy for symptomatic hyperextension-varus thrust. Am J Sports Med., 32: 6070.

9- Shim JS, Lee SH, Jung HJ, Lee HI (2013): High tibial open wedge osteotomy below the tibial tubercle: Clinical and radiographic results. Knee Surg Sports Traumatol Arthrosc., 21: 57-63. 